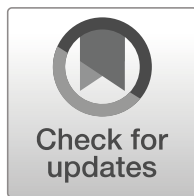

\title{
Accountability on the Fly - Accounting for Trouble in Space Operations
}

\author{
Petter Grytten Almklov ${ }^{1,3 *}$ (1), Kristin Halvorsen ${ }^{2} \&$ Jens Petter Johansen ${ }^{3}$ \\ *1 Department of Sociology and Political Science, Norwegian University of Science and Technology, \\ NTNU Dragvoll, 7491 Trondheim, Norway ; ${ }^{2}$ Department of Language and Literature, Norwegian \\ University of Science and Technology, Trondheim, Norway ; ${ }^{3}$ NTNU Social Research, Trondheim, \\ Norway
}

\begin{abstract}
The International Space Station (ISS) is research infrastructure enabling experiments in a microgravity environment. Building on a study of one of the ground control rooms in the ISS network, this paper concentrates on low-level operators and their efforts to display accountability in situations of trouble and problem solving. While the research infrastructure around the ISS is permeated by structural (bureaucratic) approaches to accountability (routines, procedures, audits and verifications), we discuss how real-time operations require a more dynamic form of continuously (re-)established accountability in the network of operators. In time-critical situations, operators need to establish accountability 'on the fly' in order to achieve the necessary agency to operate and troubleshoot their system. One key resource for this is the established voice loop system for synchronous communication. With significant constraints on the form and content of speaking turns, operators need to provide appropriate and recognizable accounts that align with the needs and expectations of the network. Based on an extensive multi-method study, with a focus here on recordings of voice loop interactions, we show how accounts of trouble are designed to manage uncertainty in the larger network, while also positioning the operators as competent and reliable members of the network. Conversely, inadequate accounts create uncertainty and delayed resolution of the issue. The design of accounts on the voice loop is crucial for time-critical articulation work in a distributed collaborative setting. The interactional details on the voice loop provide insights into the production and display of accountability, particularly relevant in networked organizations in which personal relations and trust can only play a marginal role and in which temporal constraints are critical. While the research literature has explored a wide variety of dimensions related to coordination and improvisation in distributed, mediated work environments, this study contributes with insights into the functions of verbal accounts in such contexts and how they may serve to supplement formal systems of accountability.
\end{abstract}

Keywords: Space operations, Accountability, Social interaction, Voice loop system, Troubleshooting, Anticipatory work, Ethnomethodology

\section{Introduction}

The International Space Station (ISS) has been a remarkable accomplishment, as a living laboratory in low orbit around the earth for more than 20 years now. The ISS contributes to significant knowledge production for stakeholders across the world, conducting experiments on topics as diverse as human biology and monitoring, 3D-printing and plant growth 
in a micro-gravity environment. ${ }^{1}$ This paper is based on a study of a group of research engineers acting as control room operators ${ }^{2}$ located in Trondheim, Norway, who are conducting biological experiments in one of the lab facilities on the ISS. In some ways, the experiments might seem relatively simple, as they are mainly concerned with documenting the early stages of growth in model plants. However, the plants are grown under microgravity conditions, and the fact that the experiment is conducted within the constraints of the ISS, presents several challenges for the operators.

The research activities on the ISS depend on a globally distributed network of organizations collaborating both in the planning and execution phases of the experiments. There are significant constraints on the research laboratories located on the ISS, particularly in terms of accessibility and safety, and this necessitates a high priority to planning and reliability. The involved organizations are constantly preoccupied with avoiding and managing risk.

The great demands for reliability and predictability within this network of organizations means that activities are highly regulated and hierarchically organized. The main mode of control, coordination and risk management is centered on accountability in the structural sense, characterized by detailed procedures, reports, verifications and formal risk management processes. These produce standardized documentations of control that circulate in the organization and are available for audit. ${ }^{3}$ There are extensive planning and verification processes in preparation for each experiment, and contingency plans are produced for a range of expected anomalies and troubles during experiment execution.

However, there is always a need for some degree of improvisation during the execution of an experiment. While the extensive procedures prepare for many possible scenarios, the execution phase is characterized by a range of coordinative issues, often with time constraints, and troubleshooting of expected and unexpected problems. One central resource for coordination and troubleshooting during experiment execution is the voice loop system for communication (see e.g. Patterson et al. 1999, 2008; Watts-Perotti and Woods 2007). With a number of channels, or loops, available for different functions and positions ${ }^{4}$ reflecting the hierarchy in the network

\footnotetext{
${ }^{1}$ For a full list of ISS experiments see: https://www.nasa.gov/mission_pages/station/research/experiments/ experiments_by_name.html

${ }^{2}$ In the real time phase the engineers are control room operators. However, though control room operations are an important part of their work, the overwhelming majority of their activities concern project planning, hardware and software development and configuration, training and testing. In a sense, their work and relation to scientists is much in line with Barley's (1996) analysis of lab technicians. Since our study is about the real time phase we refer to them as operators rather than R\&D Engineers (their formal title) or technicians.

${ }^{3}$ Reflecting Power's (2007) discussion of risk and uncertainty management in modern organizations. See also the theory section of Bossen (2011) for more on accountability and coordination.

${ }^{4}$ In line with the local terminology we will use the notion of 'position' for actors in the network throughout this paper. For example, the EMCS operator located in Trondheim and the Payload Operations Director (POD) located in Huntsville represent two different positions, with specific roles and tasks concerning the experiment, technical equipment and place in the network, but manned by different persons over the course of an experiment. Also within the EMCS control room, a position is a both a reference to dedicated roles and responsibilities and a physical position at a specific desk.
} 
of control rooms, this technology allows operators across the globe to speak to other control rooms and to listen in on interactions between other operators. The voice loop system is the key coordinative channel for time-critical questions, clarifications, or requests for permissions or interventions. It is a strictly regulated communication space that poses significant constraints on the operators in terms of how participation can take place. It is therefore a particular intention in the current study to explore how low-level ground control operators manage the constraints of the voice loop system, specifically the manner in which they provide verbal accounts that describe the situation, the problem at hand, and their current needs. The accounts serve a purpose both in gaining permission to act, and to protect the system against interventions or delays that can harm the experiment flow. While precise and appropriately designed accounts are imperative for coordinating and solving normal troubles as well as unanticipated errors, they also function to re-establish the control room's and the operators' position in the network, contributing to establishing what we here refer to as "accountability on the fly".

Accountability in this complex organizational setting is, in other words, a phenomenon that needs to be studied not only in terms of the formal risk management structures but also in terms of the dynamic, ongoing interaction between operators at the ground level. The "particular, concrete circumstances" in which the operators' actions and utterances are situated (Suchman 2007, p. 26) are dominated by the fact that they work within an extremely risk-averse networked organization. Furthermore, while the operators are experts on their own system, they belong to a minor peripheral node in the vast space research organization, low in the hierarchy of ISS operations. Another key to understanding their communicative choices on the voice loop is the fact that their experiments are planned years in advance, but in the execution phase need to follow a specific temporal trajectory. This is illustrated by a prominent artefact in the control room, a timeline visualization displayed on the main wall screen at all times. The "onboard shorttime plan viewer" displays all scheduled activities on board the ISS as well as periods of communication coverage and communication shadows. In the "real time phase", managing the temporal flow of the experiment is among the operators' key task. In the following we will expand on these contextual characteristics before we, in our analysis and discussion, pay specific attention to the discursive choices that operators make in a selection of troubleshooting situations. Verbal accounts on the loop are key actions that might or might not give them the necessary leeway to solve problems as they occur. The manner in which the operators use language to account for specific situations and describe unexpected situations are in other words highly relevant for their continued position in the network, and their success in keeping a timely and un-interrupted scientific experiment.

The study builds on Johansen et al. (2016), who unpacks the intricate relationship between planning and improvisation in this context, and who also coin the term 
"anticipatory work" to analyze the always forward-looking orientation of the operators and the distributed cognition (Hutchins and Klausen 1996) of which they are part. Notably, that article elaborates the distinctions and interconnections between the anticipatory work in planning ${ }^{6}$ and in work conducted in the real time phase.

The examples we describe are from anomaly responses in a distributed organization. This actualizes the concept of articulation work, a mainstay in CSCW (Schmidt and Bannon 1992), originating from Strauss (1985). Articulation work particularly highlights the situated practices of aligning tasks and resources in varying circumstances. In a discussion of the two different modalities articulation work, "ad hoc alignment and improvisation on the basis of mutual awareness versus coordination in terms of a predefined flow of work", Schmidt and Simone (2000, p. 205) stress the interwoven relationship between the two forms, that they are seamlessly meshed and blended in real life cooperative activities. We will also see a similarly blended relationship between the formal and informal ways of ensuring accountability in the real time operations.

Before exploring the concept of accountability in greater detail, discussing literature that views it as a structural and as an interactional phenomenon, we provide some central background on the empirical context of control room operations and the specifics of the voice loop system. The data and methods for our study are then described. The analysis provides examples of situations in which both expected and unexpected anomalies occur in the control room and shows how the operator accounts on the voice loop need to address the concerns of the other positions in the network and continuously reassure the superior functions that any anomalies are contained and controlled. We elaborate how accountability needs to be established interactionally, "on the fly", and how this is particularly important for operators placed low in a hierarchy of formal authority. Their key concern is to manage the execution of the experiment according within the temporal constraints (e.g. growth periods and timing of sampling). Their discursive strategies can be seen as in light of a need to reassure other actors higher in the hierarchy that they are in control of their system, and also in connection with troubleshooting and other interventions to gain priority and access to resources on the ISS.

\section{Background}

In order to conduct the multitude of parallel scientific experiments on the ISS, a large network of ground operators is in place across Europe, Asia, and North-America,

\footnotetext{
${ }^{5}$ The concept is broadly overlapping with the simultaneously proposed concept of "anticipation work" by Steinhardt and Jackson (2015) and Clarke (2015).

${ }^{6}$ Arguably anticipation is an essential element of planning generally. The discussion of anticipatory work in Johansen et al. (2016) stresses the specifics of its sociotechnical and situated nature in space research, and its connection to operational anticipatory work. See Redaelli and Carassa (2018) for a discussion of anticipation in planning on airports, which also includes discussion of temporalities that are relevant for this paper.
} 
contributing to monitoring and controlling the technical equipment that is used for these experiments. One of these control rooms was placed in Trondheim, Norway, supporting research on plant growth in a micro-gravity miniature greenhouse called the European Modular Cultivation System (EMCS). Scientific experiments were conducted regularly here between 2006 and 2018. The facility enabled fundamental biological research on the cellular mechanisms in plants, by growing plants in several experiment-runs with different gravity and light parameters. The scientific output was plant material grown in the greenhouse, frozen down post-experiment, and shipped back to earth for further study. Another key output was extensive photo and video data documenting the growth process, regularly transmitted to the ground operators. The reliability of this research is contingent on replicability between the planned and executed growth conditions as well as between the experiment runs. Thus, keeping the system in a nominal state, adhering to the strict time schedules and experiment sequences, and solving anomalies before they impact the experiment flow, is crucial for the quality of the scientific data. Years of planning and substantial economic investments have been devoted to each ISS experiment. The integrity of the technical equipment and crew safety is of utmost importance, placing great responsibility on the network ground operators who monitor the systems at all times during operations.

In addition to the high stakes, the ISS experiments are characterized by significant limitations, inter-dependencies and uncertainties. Time constraints dominate in the real time phase. These include the strict schedules of the astronauts and the experiment sequences, as well as limitations in the communication window between astronauts and ground. Resources such as water, power, nitrogen and spare parts are limited, as well as space for storage, and this places strict requirements on planning and on the possibilities for handling anomalies during experiments. There is also high degree of interdependency between parallel and sequential experiments or crew activities, and even external uncertainties can impact the operations, for example the weather conditions at the launch sites in Florida and California that can delay access to equipment or shift the time window for experiment execution. Unforeseen loss in communication between the ISS and ground operators can potentially disrupt key activities in the experiments. Moreover, partly caused by the age of the equipment, some known recurring technical issues tend to arise.

Problem solving in ground control operations typically concerns responses to anomalies in the system, diversions from the planned activities or unexpected events. The complexity of anomaly response across teams has been widely studied in a human-spaceflight setting (i.e. Watts-Perotti and Woods 2007, 2009; Johansen et al. 2016; Mohammad et al. 2014) and recently synthesized in an overview of resilient anomaly response in mission control centers (Watts-Englert et al. 2018b). As mentioned, we previously coined the concept of anticipatory work to describe the sociotechnical work processes leading up to experiments, the forward-looking 
activities during the real time phase, ${ }^{7}$ and the interrelations between the two (Johansen et al. 2016). As part of the planning phase anticipatory work, the operators prepare for a number of possible contingencies, and generate both technical fixes, procedures and scripts as well as routines with several layers of backup routines on how to fix events that might show up. ${ }^{8}$ The preparatory stages of the experiment are characterized by intense scrutiny of what might go wrong, as well as possible preventative measures. In the real-time phase, a key aspect of anticipatory work is to manage and stay ahead of the temporal constraints of the evolving situation with intermittent (but pre-identified) communication black-outs, simultaneous parallel activities, and the strict schedule of a biological experiment.

This is similar to other operational settings where professionals need to coordinate their efforts continuously and urgently in response to constantly changing circumstances. This has been studied in a number of complex organizations in which responsibility is distributed and fragmented, and in which coordination is highly mediated by technology; such as airport control rooms (Goodwin and Goodwin 1996; Suchman 1997); underground traffic control rooms (Heath and Luff 1992, 2000); emergency and dispatch centers (Whalen 1995; Zimmerman 1992); airplane cockpits (Nevile 2004); critical infrastructure (Roe and Schulman 2008).

Plans abound also in the real time phase, and the preparatory work is invaluable for the experiment execution. However, real time operations are also characterized by improvised actions that align within the temporal trajectories of operations at the ISS. In the current paper, we expand on the communicative practices of the low-level operators in real-time operations.

\subsection{Real-time communication on the voice loop system}

While the distributed organization shares real-time visual representations (live video), procedure tools, schedules and various asynchronous communication tools (email, messaging systems), the voice loop system is the pulse of the communication between the control rooms. For EMCS experiments, the control room operators rely on the ability to communicate verbally with the responsible functions in NASA and ESA for receiving and sharing information, and for obtaining permission to perform interventions.

Voice loop is an established tool in sectors such as air traffic management, aircraft carrier operations, emergency services and space shuttle mission control. It is an auditory groupware technology that supports synchronous communication on multiple channels among groups of people who are geographically distributed. As

\footnotetext{
${ }^{7}$ See the discussion of anticipation in Patterson et al. (1999) and Rosness et al. (2016) prospective sensemaking for other takes on this.

${ }^{8}$ The seamless way that anticipation and remediating measures for possible problems are distributed among hardware, software, scripts, procedures and training is the reason we stress that anticipatory work is sociotechnical, and that it goes far beyond anticipation as a cognitive process.
} 
Watts et al. (1996) and Caldwell (2005) note, this collaborative aid is particularly useful as it facilitates multichannel monitoring of communication, allowing for the extraction of relevant information and cues as well as conducting synchronization of information on several levels, from the detailed and technical to overviews. The different voice loops have different functions, with defined listening and speaking rights for each loop. The individual operator typically monitors several voice loops, while only speaking on a few. The voice loop communication system supports coordination and allows practitioners to listen in without disrupting their own activities or those of others. The system is structured around the mission control organization, and therefore meets the demands of the domain (Patterson et al. 1999, 2008). The mission control organization for ISS experiments include a wide hierarchy of positions with different responsibilities, each with a dedicated voice loop. ${ }^{9}$

As a 'one at a time'- technology, the voice loop system does not support overlapping or simultaneous talk, and there is no room for traditional backchanneling or minimal responses from the listener. The interaction on the system is largely characterized by standardized forms and phraseology leaving limited room for small talk or relational talk. Communication on the voice loop is an important part of the operator training program, detailing voice procedures, call signs, standardized response phrases in order to minimalize misreading and errors. One example is the standardized phrase for displaying attention, "copy that", and for compliance, "affirmative" or "wilco". These are not just signaling attention and precision in communication, they also indicate operator accountability, signaling that the codes and the distribution of responsibilities is shared and mutually understood. By uttering the words "copy that", the operator marks that the message is received, the content of the message is understood, and the implications of this for the role or subsystem (i.e. EMCS) are under control. Failure to signal this overall accountability related to one's position in the larger network, will have consequences for future action and, in turn, for the operator's access and agency in a problem-solving situation. While the EMCS operator train to be "precise and concise" and use standardized phraseology when talking on the voice loop, their training also stresses the importance of avoiding the spread uncertainty. For example, in training the operators are explicitly told that they should avoid uttering the words "I don't know" and instead always be solutionoriented and point towards the next steps of assessment.

All interventions from the operators, for example initiating a command script to fix an anomaly, must be verbally expressed and accounted for on the relevant loop in order for the responsible authority to authorize the intervention. When an operator wants to make an intervention that might possibly affect other activities or systems, they have to make a case to gain access. This is similar to air traffic control where Malakis et al. (2010) highlight the importance of advocating and defending own

\footnotetext{
${ }^{9}$ The relevant positions will be described in the examples in the analysis chapter, but a detailed description of the control room positions and voice loops for EMCS experiments have also been described by Mohammad et al. (2014).
} 
position in handling traffic situations. Mohammad et al.'s (2014) study of a simulation of an EMCS experiment ${ }^{10}$ found that the operators drew on communicative strategies such as providing "heads up" messages, continuous reminders or "pushing" on the other positions when closing in on critical time constraints.

Anticipatory work in real-time operations relies heavily on the voice loop system. Patterson et al. (1999) observe how listening to voice loops is essential for staying ahead of upcoming issues. They describe, for example, how active listening can make operators prepared to answer questions from the Flight Director: "When controllers hear about the failure on the Flight Director's loop, they can anticipate related questions from the flight director and prepare to answer them without delay" (p. 361). While Patterson et al. (1999) studied flight operations, the principle is the same for the organization managing ISS experiments, as operators listen in to voice loops that might give them an overview of events that might affect them. The EMCS operators listen in on relevant loops to be informed and to anticipate upcoming events, problems or opportunities. They are not only receivers responding to information from the high-level loops, but also utilize the system actively to coordinate and perform their designated tasks.

In this paper we dive deeper into how low-level operators work to establish accountability through their interaction on the voice loop, and how verbal accounts are central for achieving necessary agency for the operators when unexpected situations occur.

\section{Accounts and accountability}

We are leaning on two different strands of research in our discussion of accountability: the literature on bureaucratic processes of accountability in organization studies, here labelled a "structural approach to accountability", and the ethnomethodological and interactional research tradition in which accountability is seen as displayed and negotiated in social interaction, here labelled an "interactional approach to accountability".

There is a multitude of approaches to the concept of accountability in other fields of inquiry, seen for example in the Public Administration review paper by Mulgan (2000), who refers to it as "an ever-expanding concept" within that field alone. For our purposes, however, we seek to understand the connections between accountability as it is negotiated and established interactionally, and accountability as it is produced through structural measures such as the production of standardized, auditable documentation.

In this journal, examples of both these strands can be found. For example, in Agre (1994) accountability is clearly linked to accounting, of representation and control of

\footnotetext{
${ }^{10}$ This entailed a computer simulated EMCS experiment (in addition to parallel simulations of other experiments) for approximately $8 \mathrm{~h}$ involving all relevant NASA/ESA positions on voice loop communication.
} 
work through formal categories of work and how this relates to the situationally contingent nature of situated practice. Also Bossen (2011), a study of Electronic Health Record systems in hospitals, focuses on accountability in the bureaucratic sense, of control of the work of doctors through written formal documentation. In contrast, Moore et al. (2007) follows an ethnomethodological tradition as they discuss how gamers represent themselves in multiplayer online games.

\subsection{Structural approach to accountability}

Organizations conducting space operations are designed to control risk. ${ }^{11}$ Moreover, as the organizations are large, this control cannot be based on interpersonal trust. Consequently, formalized risk control systems dominate the organization. An increasing focus on structural accountability as a means to control risk and uncertainty is a general tendency for modern organizations (Power 2007; Dekker 2014). Power (Power 1994, 2007) sees the increasing control of uncertainty and risk as yet another manifestation of the "audit explosion", where the logic of audit-based accountability is the primary way of producing organizationally visible evidence of control, also of risk and uncertainty. Along similar lines, Dekker $(2014,2017)$ observes that organizations today tend to focus on bureaucratic accountability, his main concern being that it may displace other ways of achieving safety in operations.

In organizational theory, organizations successfully managing risk in complex environments have often been studied in the High Reliability Organizations (HRO) strand of theory (LaPorte and Consolini 1991; Weick and Sutcliffe 2007; Roe and Schulman 2008). ${ }^{12}$ Within this body of research some principles of organizing that are typical for organizations that successfully manage risk in complex situations are extracted from detailed case studies. In a discussion of whether NASA could be regarded as a HRO, Casler (2014) concludes that the NASA organization does not exhibit the typical HRO characteristics. As a vast, public mega-organization it cannot be expected to live up to these ideals. However, when studying more dedicated mission organizations such as the projects the case organization for this study takes part in, both for NASA and ESA, several typical HRO characteristics are highly evident. Among these are a focus on redundancy, a reluctance to simplify and a pervasive preoccupation with failure (see Weick and Sutcliffe 2007). The experiment - equipment, protocols, procedures, plans - are subjected to layers upon layers of formalized control and verification before it gets the go ahead. In the planning phase

\footnotetext{
${ }^{11}$ Important discussions of risk control, and its failure, in space operations is found in the post disaster studies of Vaughan's (1996) book The Challenger launch decision and the edited volume by Starbuck and Farjoun (2005) in the aftermath of the Columbia accident.

${ }^{12}$ The HRO literature is often regarded as a response to the challenge posed by Charles Perrow's (1984) Normal Accident Theory which argued that the combination of interactive complexity and tight couplings meant that some systems were prone to systemic accidents. Based on a series of case studies, HRO researchers sought to identify and understand traits of organizations that were successful in coping with these challenges.
} 
every aspect of the project is documented, verified and certified in advance through formalized risk control systems. Risks are studied and documented, uncertainty is sought reduced to a minimum through detailed documentation, verifications, audits, simulations and revisions. ${ }^{13}$

Within HRO and the organizational literature generally ${ }^{14}$ there is an increasing recognition of the shortcomings of formal systems of accountability regulating the dynamic, situationally contingent execution of operational work. In recent studies we have ourselves also addressed the relationship between systems of accountability and the temporality of the work situation (Almklov and Antonsen 2014; Almklov 2018), arguing that some forms of work and aspects of work are poorly aligned with such systems. As we will elaborate here as well, the temporality of the real time phase of space operations necessitates a change in how risk is controlled as soon as the experiment is commenced.

The preoccupation with previous and possible failures and the reluctance to simplify are clearly seen in the planning phase of experiments. For a single experiment this phase lasts for years, from the conception of the idea by the researchers, through the design of the plant cassette to the detailed planning of the project execution with computer scripts and interventions (with fall back options), test runs and simulations and operator training. All these steps are documented and verified in detail both internally in the organization in Norway and by external partners in the network. In this phase, standardization, systems of verifications and audits are ways to make sure that the organizations involved in operations are reliable.

As our examples will show also, the authorities in central positions in the network (representatives of NASA and ESA) are always on watch for any signals of risk. However, when the real-time phase of the operations starts, the time constraints make it impossible to conduct formal audits of the changes and adjustments that occur during operations. In this real-time phase of operations, control of risk needs to be established by other means, as we will illustrate, through real-time interactions between operators and managers across the different units and control rooms in the ISS network. A key resource for this interaction, particularly in trouble shooting situations, is the voice loop system.

The network of collaborating organizations consists of a multitude of actors, and where personal relations are limited. The exchanges on the voice loop occur predominantly between people that do not know each other personally. Collaboration is thus based on knowing the positions in the network rather than the people. In this situation, the interactions on the voice loop are important for coordinating trouble shooting, but also for negotiating whether or not risk is under control. During the

\footnotetext{
${ }^{13}$ See for example Sgobba et al. (2018a, b) for a description of system safety engineering in space operations and our own Johansen et al. (2016) for more on the planning phase of from the perspective of our operators. Mohammad et al. (2014) describes a full-scale simulation run of an experiment on the EMCS, which is an important step in these validations.

${ }^{14}$ Most notably the Resilience Engineering strand (Hollnagel et al. 2006).
} 
real-time phase, risk, reliability and accountability are temporary and precarious phenomena.

\subsection{Interactional approach to accountability}

In order to catch this precariousness of accountability, we turn to the field of ethnomethodology and Garfinkel's (1967) approach to accountability as he described it in relation to human action and interaction. Rather than seeing accountability as established through formal documentation, verification and regulation, this approach acknowledges the many ways in which social actors display and negotiate accountability in everyday social action. The concept of accountability from this strand of research helps us understand how social actors present themselves in "orderly" ways to each other. From an ethnomethodological perspective, social organization does not simply occur from formal process descriptions or organizational charts. Social structures are created, maintained and modified through people's behavior and through people's actions and interactions. In order to be recognized as a legitimate and competent member of the given group, accountability needs to be displayed and re-established continuously through acting and interacting in ways that are acceptable and recognizable for other people in the community. Accountability, from this perspective, is something that is talked into being and negotiated in interaction, elicited and accomplished in expressions and actions of everyday work and interaction.

One significant resource available for social actors in presenting themselves to the world and for displaying social accountability, are verbal accounts (Orbuch 1997). Accounts are, in this context, situational descriptions in which speakers attend to a specific content by establishing facts, identifying causes, backing up claims, providing explanations, or justifying actions. These descriptions also inevitably attend to relational aspects by implicating motives and intentions, assigning responsibility, and managing credibility. Accounts reflect, in other words, culturally embedded and normative explanations within the contexts in which they are given. In this way, accounts provide a rich intake into the rationalities and relations that are recurring in specific activities, such as the execution and monitoring of a scientific experiment.

Accounts are defined as explanations or justifications for actions that are unexpected or potentially inappropriate (Scott and Lyman 1968). Ethnomethodological and interactional studies have been concerned with accounting practices in a variety of contributions since the 1960s, inspired by Goffman's (1959) attention to the moral commitments of social interaction and people's ways of presenting themselves to others (Heritage 1988; Buttny 1993; Robinson 2016), as well as Garfinkel's (1967) interest in the minute details of human social order. From the field of Conversation Analysis, studies have shown how accounts are interactionally designed with reference to how they will be recognized and understood by others and as constructing preferred meanings for problematic events (Antaki 1994). The concept of 'recipient design' (Sacks et al. 1974) describes how talk in various ways are designed for 
displaying the speaker's orientation to co-participants. In the context of space operations, accounts are made verbally on the voice loop, to one or more relevant functions that have the authority to grant permission or to accept/reject the contribution - with a distributed, partly unknown audience of overhearers (Goffman 1981) across the world. The manner in which EMCS operators account for trouble, then, can tell us something about the larger social structures that surround the accounting practices and the expectations that are embedded in them.

The fields of CSCW and Workplace Studies have contributed significantly to our understanding of the situated and social character of collaborative work, particularly by supplementing lab-based research with "naturalistic" (Heath and Luff 1992, p 70) analyses in technology-supported work environments. Ethnographic and ethnomethodological studies are among these approaches that have provided detailed and systematic studies of mediated social interaction and its functions in complex, collaborative practices (Button 1993; Heath and Luff 1992, 2000, Suchman 1997, 2007; Resnick et al. 1997; Hoeppe 2019). In this study, we are particularly interested in the accounts given by the operators on the voice loop as part of a problem-solving situation. In order to gain permission to act, the operator needs to account for the necessity and relevance of the action and establish legitimacy as a competent and accountable member of the network. The account must, in other words, be produced in a manner that is recognizable and appropriate in the ears of the receiver. Their interactions on the voice loop have implications for the experiment execution, but their design is also, as we will demonstrate, aimed at producing accountability "on the fly", thus supplementing more formal systems of accountability in the organization.

\section{Data and Methods}

The current analysis is based on data gathered in the period of 2013-2015, through a period of ethnographic studies with participant observation of all activities surrounding the control room. In addition to field notes, comprehensive data material was collected: plans, technical documentation, procedures, formal and informal interviews with ground operators and observation of experiments. Particularly foregrounded in this paper, are video recordings of operators and their main screens in the control room during the running of a specific experiment at the ISS. The video analyses are contextualized and elaborated based on the extensive ethnographic interaction with the control room over years, during both planning and execution of the experiments.

The control room and the research group belong to separate departments of the same research institute and have collaborated over several years in research and development activities. The research activities have resulted in several scientific papers with collaborative authorship between researchers and technicians. One of the authors of this paper has, as a part of this research project, completed certification in the operator training program and has participated in subsequent experiments as an 
operator, while also working as a researcher. Frequent interactions of different kinds with the operators over time and in different situations position us strategically to contextualize the control room interactions within a broader understanding of their activities. $^{15}$

The experiment referred to in this article was conducted on the ISS in $2014 .{ }^{16}$ Simply put, this was part of a series of plant biology experiments that aimed to provide a better understanding of cellular mechanisms invoked at different gravity thresholds. While the experiment flow followed automatically programmed sequences, the ground operators needed to conduct a set of interventions as well as coordinate and support manual astronaut activities (inserting, removing, and fixating the plants at specific times). These activities must be aligned with other activities and fit the ISS workflow with its strict constraints in terms of time and resources. All interaction with the ISS, either sending computer commands or supporting the astronauts, need to be approved by different positions in the network depending on the nature and necessity of the activity. While verbal coordination through the voice loop is necessary even for nominal activities, anomalies and troubleshooting activities normally lead to high activity on the loop. Our analytical vantage point differs from the studies conducted by Patterson, Watts and colleagues (Patterson et al. 1999; Watts et al. 1996) in the respect that we place the work and voice loop communication of low-level operators at the center of our analysis.

With permission from local management and consent from all co-located ground operators, we were allowed to install two video cameras in the control room and monitor the entire operation. This resulted in $96 \mathrm{~h}$ of recorded data, including all active sound loops and in-room sound in the control room.

The semi-open features of the voice loops represent a challenge in terms of consent to record sound. It is virtually impossible to know which persons are talking or listening on the loops at any time. However, its openness, the fact that there is at any time an indefinite number of people listening in, means that speakers are aware that this is not a medium for sensitive communication. Excerpts from the voice loop can for example be recorded for use in training in the involved organizations. Given this semi-open nature of the voice loop channel, and the fact that acquiring consent from all possible speakers on the voice loop would be an impossible task, we have sampled the communication sequences that are experiment-specific and in which the Trondheim control room was in charge. The analysis has had an explicit focus on the local operators' discourse on the voice loop, and only included other people's talk in order to contextualize the analysis. We have carefully followed the principle of beneficence, designing the project to do no harm and to maximize the benefits for

\footnotetext{
${ }^{15}$ See Pollock and Williams (2010, p 532) for a discussion of strategic ethnography. Though not fully similar to our approach - our study is not multi-sited and concerned with innovation- our positioning is well designed to "tackle extended timeframes, trough more complex temporal designs including longitudinal studies, followup studies and long-term historical investigations."

${ }^{16} \mathrm{https}: / /$ samforsk.no/n-usoc/Pages/Experiments/GRAVI-2.aspx
} 
participants. No speakers external to the Trondheim control room has been focus of analysis, and the local operators have been included in discussion and reflections based on excerpts from the data. None of the examples of troubleshooting in this material has been controversial in nature or represented any impact outside the EMCS experiments. They do not reflect negatively on actors external to the EMCS control room. The material has been discussed with control room operators both for purposes of validity and relevance of the research findings as well as for learning and feedback to the control room community.

Our analytical strategy was to first analyze the console logs, which are timeannotated and manually written by each ground operator during the experiment, documenting all nominal check points, possible anomalies as well as interaction with other positions in the network. In this analysis we identified all troubleshooting situations which could potentially be interesting to investigate further. The video recordings of these situations were then reviewed and narrowed down to a few representative examples which were isolated in short segments (around 2-15 min). The interactions within these segments were then transcribed and analyzed in detail. The main data presented in this paper is transcribed excerpts from the active voice loops and conversations between the operators. The video data was primarily utilized in joint sessions to analyze the in-room activities, verify indicators on screen (i.e. telemetry error, loose cable), as well as the behavior of the operators (i.e. are they taking notes before talking on loop, which screens they are checking etc). Thus, the video material mainly features as the basis for the situational descriptions. Analysis was mainly performed in joint sessions within the research team: one specialist in applied linguistics with experience from research on technical, high-risk settings; one anthropologist with extensive experience from observing work in this and other control rooms, and; one sociologist and certified control room operator with extensive field work experience in the EMCS control room. Without extensive knowledge of the control room setting, technical systems, planning process, communication protocols and the challenges they need to address during the experiments these data would be very hard to analyze. They still are, especially since there is a great number of voice loops, sometimes in use simultaneously. This posed a challenge in accurately transcribing of all communication connected to the events under scrutiny. However, the breadth in our data material, including the possibility to discuss with operators what the probable meaning of garbled utterances are, makes it unlikely that significant meaning is lost due to this.

\section{Analysis}

The ISS network is geared to avoid and control risk, such as events threatening the safety of crew or equipment, or the scientific output of the experiments; the main objective and subsistence of the ISS. In planning and preparations this is done through layers upon layers of verifications and audits usually spanning several years. The moment the seed is watered and the experiment starts, time becomes critical, 
with temporal constraints bounding the experiment trajectory. Deviating from the temporal flow of the experiment, delays in interventions, imaging or sampling impact the scientific output and the project success. Thus, in this phase the EMCS operators are the "guardians of the experiment trajectory". ${ }^{17}$ When problems occur, be it the "normal, natural troubles" (Garfinkel 1967) of their technical system, minor or more challenging malfunctions or errors, time rarely allows for systematic validation of their actions beyond what has been done when contingency plans were made in advance. Thus, decisions to require formal validation of troubles, anomalies or mitigating actions in cases of uncertainty would likely imply leaving the real-time mode, with associated loss of scientific data from the experiment. As low-level operators in a hierarchical organization which is highly conservative to risk, the operators continuously need to reassure their colleagues that they are in control of their system, their interventions on it and the effects they might have on other ISS systems, in order to keep troubleshooting in real-time mode. In the real time phase, accountability is hard to achieve by bureaucratic means, so the accounts on the loop are an important part of this reassurance.

We will demonstrate how the operators work to design their communication on the voice loop in ways that serve to establish a sense of accountability and preparedness on behalf of the control room. The first two examples show operators accounting for what they identify as known problems in the system and requesting permission to act on it. The last two examples show operators managing unforeseen problems, and we draw attention to the consequences of inadequate accounts on the voice loop. These inadequate responses create uncertainty in the larger network and repeated rounds of questions and confirmations from other positions. The examples below illustrate situations where the EMCS operators' accounts on the voice loop are successful and fail to produce accountability on the fly.

\subsection{Gaining access to troubleshooting familiar problems}

During the 12 years of experiments on the EMCS, several anomalies have been experienced, resolved and documented in a database available for all positions in the network, the Payload Anomaly Reports (PAR). Although these anomalies are anticipated, they are often only known by the EMCS operators and not the other positions in the network. Thus, a key task when such events occur is to inform the relevant positions in the network about the issue and gain permission to perform actions to resolve it. We here show two examples of how accounts are constructed of the recurring anomaly of unstable telemetry between the EMCS and ground operators. While this anomaly in itself is not directly impacting the scientific output or experiment flow, loss of telemetry means that the operators are unable to see the

\footnotetext{
${ }^{17}$ This has parallels to the temporal dimensions of other control rooms. The phrase here is a nod to Heath and Luff's (1992, p73) description of the "guardian of the time table" in underground control rooms.
} 
status of the greenhouse and this can potentially be acute if it coincides with manual command sequences, critical experiment activities or other anomalies.

\subsubsection{Example 1: Unstable telemetry I}

It is a night shift with only one EMCS operator on duty. Suddenly, the screen starts blinking in an unusual way, alternating between green and blue (respectively indicating whether the computer is receiving telemetry or not). Since the ISS at that time is within good telecommunications coverage, the blinking is most likely an indication of unstable telemetry caused by an interface error between the EMCS internal computer and the external computer rack on the ISS. This is a previously documented anomaly. The operator contacts the Payload Operations Director (POD) on the POD loop in order to gain permission to perform system commands that might restore the signals. ${ }^{18}$

\begin{tabular}{|c|c|c|c|}
\hline & Speaker & Loop & Message \\
\hline 1 & EMCS & POD & POD EMCS Ops your loop \\
\hline 2 & POD & POD & EMCS Ops this is POD go ahead \\
\hline 3 & EMCS & POD & $\begin{array}{l}\text { Yes sir, I am experiencing unstable telemetry from the EMCS, I believe } \\
\text { this is related to the PAR EMCS SW } 16 \text {. We have a Fix telemetry } \\
\text { schedule that usually fixes this problem so I would like to command this } \\
\text { schedule to start. }\end{array}$ \\
\hline 4 & POD & POD & $\begin{array}{l}\text { Alright, you are getting unstable telemetry signature which you have seen } \\
\text { before and you think you have a corrective, which is to start a schedule }\end{array}$ \\
\hline 5 & EMCS & POD & That's affirmative \\
\hline 6 & POD & POD & $\begin{array}{l}\text { Alright, when you say unstable is it sort of like intermittently dropping in } \\
\text { and out? }\end{array}$ \\
\hline 7 & EMCS & POD & That's affirmative, it's dropping in and out. \\
\hline 8 & POD & POD & One second. \\
\hline
\end{tabular}

\section{Excerpt 1: Unstable telemetry I}

The opening sequence in voice loop communication is standardized and consists of a summons-answer sequence. The caller summons by naming the addressee first, then identifies herself and the voice loop that is being used (turn 1).

The summoning is followed by an answer (turn 2) that contains both recognition of caller (EMCS) and identification of speaker (POD), as well as an explicit permission to speak ("go ahead"). The summons-answer sequence resembles the opening of traditional telephone calls (Sacks et al. 1974), as it establishes contact, ascertains availability, and provides identification and recognition. This ensures a working channel of communication and assurance of availability, which is highly

${ }^{18}$ The POD loop is monitored by all positions working on NASA- and ESA-owned experiments. By using this loop all positions receive a heads up regarding the issue. 
relevant in the context of an extended network of operators, a high number of voice loops, and the many possible activities in which each location might be involved.

Once the communication is opened, the operator provides an account for the telemetry situation and presents a request for permission from POD to perform the command that will solve the issue (turn 3 ). The operator begins by giving a concise description of the problem (unstable telemetry), framed as a current, immediate problem (I am experiencing). He then quickly provides a tentative explanation for the problem, with reference to the PAR, and thereby signals that this is a known anomaly. Immediately following this assessment, the operator continues to inform that a procedure exists to solve the problem and that he has available a previously tested solution ('usually fixes the problem'). As he presents this solution, the operator shifts form the singular to the plural first person pronoun (from 'I' to 'we'), which grants his proposal added weight and institutional anchoring. This is not a solution conjured up by the operator himself, but an institutionally sanctioned and tested solution. With the discourse marker "so", the operator presents the logical consequence of his account, namely that he gets permission to execute the schedule that might remedy the problem. The request is formulated in a polite and mitigated form ("I would like to"), which mirrors the general tone and style that is used in communication on the loop (perhaps most clearly pronounced by the native speakers of American English).

Summarized, the account is persuasive in structure providing a problem description, an assessment of cause, a solution and a request for action in one concentrated, logical account. The tone is appropriate and there are few hedges, hesitations or pauses that might signal uncertainty or doubt. There are no unnecessary descriptions or explanation that might take the attention away from the essential elements of the request.

The addressee (POD) responds by acknowledging receipt (all right) and by reading back, as is standard procedure, an abbreviated version what he has heard. The operator confirms that the summary is correct with a standard response ("that's affirmative").

Before moving on, POD calls for further clarification of the nature of the problem and proposes an added description of the problem as 'intermittently dropping in and out'. This indicates that he in the meantime has checked the PAR, which contains this exact description. The EMCS operator confirms again in the standard phrase, adding an echo of the description given (dropping in and out). This concludes this sequence and POD uses the idiomatic expression 'one second' to put the conversation on hold while he moves to another voice loop to provide EMCS the permission to perform the command.

The authors discussed this excerpt with a group of operators, and they expressed a feeling that the account seemed rehearsed and they suspected the operator had taken notes in advance since the first indications of the problem in fact had started an hour prior to this excerpt. We do not know whether this is in fact the case, but from a research point of view this reflection from the operators is interesting. A rehearsed account might serve as a form of impression management (Goffman 1959), in which the operator monitors and controls his self-presentation on the voice loop by rehearsing an account of the potential problem. 
This very same issue occurred when the third author of this paper had his first night shift alone as an operator. He was prepared for the issue through his training and preparations and intended to run the script to fix it. He contacts the Huntsville control room for permission. According to normal practice, Huntsville asks him "Have you done this before?". The operator responds "affirmative, we have done this before." In discussions with the team (of operators and researchers) afterwards he expresses doubts about his response. "It felt like I was lying, because I hadn't done this before at all." A more experienced operator disagrees: "When you answer, you answer for us. They are not asking about you specifically. They are enquiring about us." And from this perspective, the operator's response makes sense. The control room as a unit had performed this operation numerous times. He himself had rehearsed the script repeatedly and seen it executed by others. His affirmative answer was not about himself as an individual, but about the position he represented. The effect of him being more truthful, maybe by specifying that he had not personally executed it, would draw attention to, and possibly delay an operation that he needed to perform. It is, in other words, not a personal kind of accountability that the operators display in their communication on the loop, but rather one of a shared, collective competence.

\subsubsection{Example 2: Unstable telemetry II}

The anomaly with telemetry is also the case in the next example, which takes place during an afternoon shift with two operators on duty. Two hours before this exchange there was instability in the transmission of telemetry and it was established that it resembled the previously experienced problem. After an initial exchange regarding small telemetry dropouts, the telemetry becomes even more unstable and the EMCS operator calls the PRO position ${ }^{19}$ in order to get permission to send a corrective command.

\begin{tabular}{|c|c|c|c|}
\hline & Speaker & Loop & Message \\
\hline 1 & EMCS & PRO & PRO EMCS Ops on your loop \\
\hline 2 & PRO & PRO & Go ahead EMCS \\
\hline 3 & EMCS & PRO & $\begin{array}{l}\text { Uh the telemetry is really unstable now and I would like to try to send } \\
\text { our command like- or uh for- try to resolve this problem, this is one } \\
\text { part of the resolution that we have for the- for the PAR uh software } \\
\text { 0016. }\end{array}$ \\
\hline 4 & PRO & PRO & Copy that. I'll get a go for those commands through POD \\
\hline
\end{tabular}

\section{Excerpt 2: Unstable telemetry II}

This account differs from the previous one, as it is less rhetorical in structure and production, perhaps simply less rehearsed than the previous example. However, it is to the point and manages to convey both the problem and the solution in a brief manner.

\footnotetext{
${ }^{19}$ The PRO position is responsible for enabling external control rooms for commanding. If there is much activity on the POD voice loops, the EMCS operators sometimes will address the PRO position directly if the issue is known or previously discussed.
} 
The operator here chooses to boost the problem description ('really unstable'), which might suggest that the problem they have seen the last two hours has increased in severity and thereby justifies his initiative to do something about it at this point.

In contrast to the first operator, the request for permission is presented immediately after the problem has been described. He also implies that the existence of a command is known to the PRO ('our command'). He then chooses to elaborate the rationale for his request by providing details of the PAR. This account might appear less confident than the previous one, with more hesitation and repairs, but this is also characteristic of naturally occurring speech and may not reflect on the reception of the account. Although produced in a less rhetorically strong format, the account achieves the same effect, which is the desired response from the addressee without delay or extra rounds of clarifications.

\subsubsection{Strategies to display control and accountability}

These two examples demonstrate how the control room operators account for problems via the voice loop system in manner that serve to downgrade and contain the perception of risk on the larger network. The issues they experience are troubles that they believe they can manage safely without needing further attention from other positions besides what is necessary to get a timely permission to run a command through the computer rack. Despite their nature as 'troubles telling' (Jefferson et al. 2015), the accounts often seem well-prepared, as the operators listen to the loop and time their message in relation to the other activities on the ISS. It is interesting that the operator presents, whether rehearsed or not, a constrained but succinct and persuasive account. He takes the linguistic resources he has available and uses them to achieve the goal of getting permission to handle the problem in an efficient manner. $\mathrm{He}$ follows the routines and procedures, refers to formal documents, and employs the standardized forms of polite address that are appropriate for this setting. The accounts are carefully designed to balance the need to convey a sense of urgency while also displaying accountability and control of the situation. Combining a sense of urgency with a "business as usual"-tone with respect to the problem they are trying to solve, should also be understood as a consequence of their interest in keeping the flow of the experiment uninterrupted and smooth. The operators are trained and constantly reminded not to spread unnecessary concern and uncertainty in the network.

In some cases, however, they choose to do the opposite. For example when battling with time constraints or access to the astronauts' time, some phrases such as suggesting the "potential for loss of science" will be employed strategically to gain the attention of senior positions to help give the EMCS priority. As with the statements downgrading risk in our cases, such statements are factually correct, however the choice of words depends on whether or not the operators want to gain the attention of other positions. When we have discussed this with operators, they stress that they are conservative about employing statements that upgrade the perception of risk, as the downside of drawing attention to themselves unnecessarily is that they appear less in control and as less accountable to other members of the network. 


\subsection{Accountability in question when faced with unexpected events}

While the two former examples are known anomalies, there are also frequently nonanticipated problems arising and cases in which the impact and resolution of the problem is unknown. Thenext two examples are such cases, and we will show how inadequate accounts of these problems on the voice loop further increases uncertainty and response iterations.

\subsubsection{Example 3: Corrupt images}

During an evening shift, the chief ESA position, Col-Flight, located in Munich, calls POD on the voice loop system and reports that they are receiving corrupted images from the EMCS. While the voice loop is often noisy, with an overload of information not relevant for each operator, the word "EMCS" (or even closely sounding words) usually should draw the attention of the operator. In such a case, a common reaction is simply to respond "EMCS here" on the loop, indicating that the operator is aware that the discussion is relevant to his control room. Alternatively, the operator can call one of the Huntsville positions immediately to make oneself available for questions.

In this case, in the EMCS control room, the operator does not experience the same problem with the images as they do in Munich (Col-Flight), and he does not hear the message given on the voice loop. The images are a vital part of the scientific output of the experiment and corrupt images could potentially diminish the value of the experiment. Consequently, EMCS is called up from a Huntsville position responsible for short-term planning, OC, who inquires about the situation:

\begin{tabular}{|c|c|c|c|}
\hline & Speaker & Loop & Message \\
\hline 1 & $\mathrm{OC}$ & $\mathrm{OC}$ & EMCS Ops OC my loop \\
\hline 2 & EMCS & OC & Go ahead OC \\
\hline 3 & $\mathrm{OC}$ & OC & $\begin{array}{l}\text { Yeah I was wondering if you could get us a better description of what the } \\
\text { problems you are having with the still pictures coming from Express Rack } 3 \text { ? }\end{array}$ \\
\hline 4 & EMCS & OC & $\begin{array}{l}\text { I don't think that we are having problem with the still pictures. We } \\
\text { are receiving the images so- }\end{array}$ \\
\hline 5 & $\mathrm{OC}$ & $\mathrm{OC}$ & $\begin{array}{l}\text { Ok we just got a report from Col-Flight that said that they are receiving } \\
\text { corrupted files for the images from Express Rack } 3 \text { is that- are you } \\
\text { unaware of that? }\end{array}$ \\
\hline 6 & EMCS & OC & No I am not unaware, I am receiving the images here also \\
\hline 7 & $\mathrm{OC}$ & $\mathrm{OC}$ & And you are happy with what you are getting? \\
\hline 8 & EMCS & OC & That's correct \\
\hline 9 & $\mathrm{OC}$ & OC & And how about the video are you getting video that you-? \\
\hline 10 & EMCS & OC & We are also (two inaudible words) yes. \\
\hline 11 & $\mathrm{OC}$ & $\mathrm{OC}$ & $\begin{array}{l}\text { Copy that, if you can listen to the POD loop we will have that discussion } \\
\text { with Col-Flight and see what it is that they are indicating as a problem }\end{array}$ \\
\hline 12 & EMCS & OC & Copy \\
\hline
\end{tabular}

\section{Excerpt 3: Corrupted images}

$\mathrm{OC}$ is calling for a description of the problem (turn 3,) which he assumes is known to the EMCS control room ("the problems you are having"). The response from EMCS 
is hedged (I don't think we are having problems", turn 4) and despite the reassurance that they are receiving images, the response is left hanging with the discourse marker "so", indicating that there might be more to say about the issue. OC responds by providing an explanation for his question (Col-Flight reports corrupted images) and he asks again for a clarification about the EMCS' knowledge about this problem. The response from EMCS in turn 6 ("no I am not unaware") might be a simple misunderstanding, or perhaps even a question of language proficiency, ${ }^{20}$ as the EMCS operator clearly is unaware of the problem and not experiencing any trouble receiving images. The continued questioning from OC (turns 7 and 8) also indicates that he needs further reassurance that the EMCS greenhouse is not suffering any technical problems. All the questions from OC are generally answered directly (and correctly) by the EMCS operator, but without providing any additional information that might reassure $\mathrm{OC}$ about the situation or address the main concerns that underlie the series of questions, namely the integrity of the scientific experiment.

Operators missing relevant conversations do happen from time to time due to disturbances on the loops, multiple conversations, moments of inattentiveness or other factors. More interesting here is how, once a perceived problem has been identified and communicated, the responses provided by the EMCS operator fail to address the fundamental question that the other positions in the network hold, namely whether there is a technical problem with the EMCS and whether this is threating the scientific data.

In this situation, the images from the EMCS to the Trondheim control room were fine. This indicated most likely a technical problem or glitch in the ground network infrastructure to Munich, not critical for the scientific output, since the images are stored in Trondheim. This conclusion was clearly and immediately visible for the EMCS operator by looking at the ongoing stream of non-corrupted images and video. However, while the EMCS Operator was correct that there was no actual anomaly in the system, his responses failed to provide sufficient information to reassure the other positions and to communicate this fact with certainty and clarity.

In contrast to the very short, almost restrained responses in this sequence, the summary later provided by the OC position to POD and Col-Flight, shows an example of greater attention to the information needs in the surrounding environment:

\begin{tabular}{lll}
\hline Speaker & Loop & Message \\
\hline OC & POD & $\begin{array}{l}\text { Yes, I checked with EMCS Ops and they said that both their still pictures } \\
\text { coming from Express Rack 3 look good to them, they don't have any } \\
\text { problems with corrupted files, nor are they having problems with their video. } \\
\text { So you may want to get a better description of what the corrupted files are }\end{array}$ \\
\hline
\end{tabular}

\section{Excerpt 4: Corrupted images, continued}

\footnotetext{
${ }^{20}$ English is the lingua franca of most of the ISS network of control rooms. Many of the operators are not native speakers of English, which sometimes leads to non-standard or imprecise expressions on the loop.
} 
In this account of the situation, OC first describes what he has done to address the situation ("checked with EMCS"), then he reports what he has found (EMCS pictures look good), and these findings are emphasized by repetition ("they don't have any problems") and by including details that has not been reported as problematic (also no problems with video). This last addition, contributes to framing the account as complete and considered, implicitly stating that the scrutiny of the problem has included more than just the status of the images. He concludes with a proposal for further action, presented as a necessary implication of this situation ("so you may want to"). This account can be seen as designed with the goal of containing and reducing any uncertainty that may exist in the larger network of control rooms.

\subsubsection{Example 4: Loose water cable}

The final example is a more complex one, as it includes a problem that not only has the potential to threaten the scientific experiment, in worst case also disturbing other operations and systems beyond that. The OC position, located in Huntsville, discovers at one point that a section of a cable is hanging down between two rotors of the greenhouse. At each 360-degree spin of the rotor (every five seconds), the cable hits the internal structure of the greenhouse. This is visible on the live video screens in the control room recorded from inside the EMCS greenhouse, but it has not been noticed by the operators in the EMCS control room. OC calls the EMCS on the loop to inquire about this problem.

\begin{tabular}{|c|c|c|c|}
\hline & Speaker & Loop & Message \\
\hline 1 & EMCS & OC & This is the EMCS yes? \\
\hline 2 & $\mathrm{OC}$ & $\mathrm{OC}$ & $\begin{array}{l}\text { Ok, we're all kind of watching the internal EMCS video and } \\
\text { (inaudible) caught that the rotor as it spins, a cable is hanging } \\
\text { down and it catches. I think that's not normal }\end{array}$ \\
\hline \multirow[t]{3}{*}{3} & EMCS & OC & Uh standby \\
\hline & Engineer & In room & Yeah I see it, I just saw it. \\
\hline & EMCS & In room & Yeah that's not good, it catches. \\
\hline 4 & EMCS & OC & You are totally correct. However we cannot do anything \\
\hline 5 & $\mathrm{OC}$ & $\mathrm{OC}$ & $\begin{array}{l}\text { Alright, not right now, uh but I mean after the first Gravi } 2 \\
\text { run between the early and the second run is there anything you } \\
\text { guys can do? Anything? }\end{array}$ \\
\hline 6 & EMCS & OC & We need to discuss this further I think \\
\hline 7 & $\mathrm{OC}$ & $\mathrm{OC}$ & Ok, uh \\
\hline 8 & EMCS & OC & Thanks a lot for letting us know \\
\hline \multirow[t]{2}{*}{9} & $\mathrm{OC}$ & $\mathrm{OC}$ & $\begin{array}{l}\text { Ok, if there is- you need help with a PAR (inaudible) just let me } \\
\text { know. }\end{array}$ \\
\hline & Engineer & In room & Not at the moment \\
\hline 10 & EMCS & OC & Copy that. Not at the moment \\
\hline
\end{tabular}

\section{Excerpt 5: Loose water cable}

The loose cable is new information for the EMCS operators, and they are surprised to see the problem on the video screen (See Fig. 1). After a brief look at the video, the 
operator reports back to OC with an acknowledgement of the problem (turn 4 "you are totally correct"). Without making any further assessment of the situation, he concludes to OC that there is nothing that can be done about this problem. The response is an extreme case formulation (Pomerantz 1986), in which the operator presents a maximized version of the situation ("we cannot do anything"). This conclusion implies that there are no possible options, which from the perspective of OC might be heard as alarming. At this point, the team has not yet established what kind of cable this is and what the implications are if it gets stuck to the EMCS holding structure while the rotor is spinning.

The response triggers further questioning from OC, who does not accept the operator's conclusion. Instead, he starts the problem-solving process by exploring possible time frames in which action might be taken (turn 5, between two runs in the experiment). The urgency of the matter is emphasized by the repetition in his request (“anything you guys can do? Anything?"). The EMCS operator does not acknowledge this specific proposal of time frame, but rather moves to closing the interaction by taking the discussion out of the voice loop system (turn 6 "we need to discuss this further I think"). In this way, he acknowledges that there is more to be said on the issue and signals that they will be searching for solutions. However, he does not relate to OC's problem-solving attempts, instead, he extends a thank you to OC for alerting them to the problem. This further shuts down any discussion with OC about possible solutions, and effectively closes the interaction.

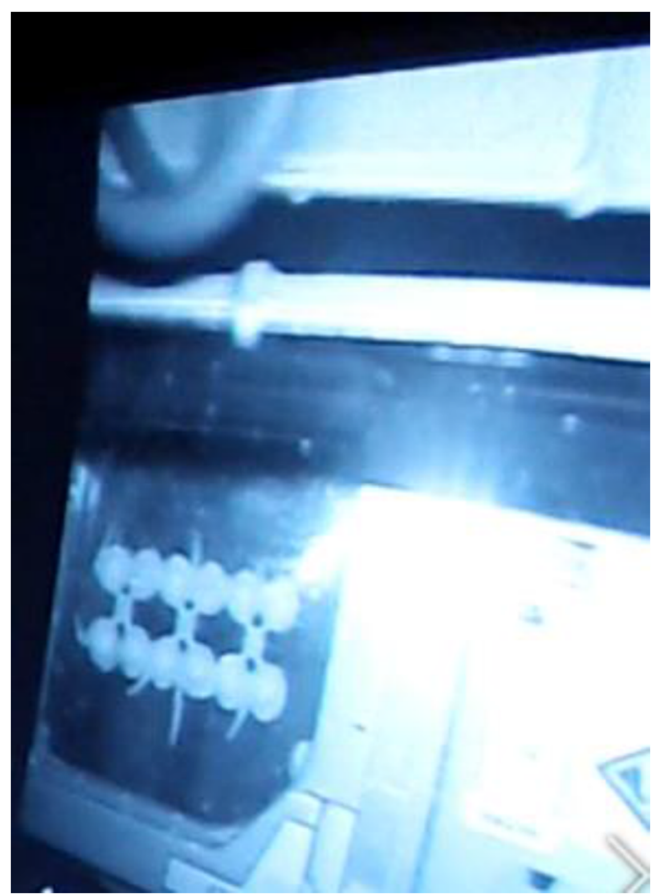

Fig. 1. Image from the internal cameras in the EMCS, drawn from the live video screen in the control room. The loose water cable is visible in the top left corner 
In the control room, the operator sits with his project leader, another operator, and two technical engineers. They are at this point discussing intensely amongst themselves, what to do about this problem. Less than three minutes later, they are called up again on the voice loop by the $\mathrm{OC}$ who wants to know more about the function of the loose cable (whether it's a water cable or power cable), indicating that they are still concerned about the issue. In order to assess the risk, they need to ascertain what kind of cable this is. With input from the engineers, the operator explains that it is a water line for the internal water supply for the green house.

Another two hours proceed without communication on the loop, while the EMCS engineering team and other operators are assessing the images and discussing the problem back stage. At this point, OC calls them up again with concerns about the situation and whether there is anything the crew on the ISS can do to manage the problem:

\begin{tabular}{|c|c|c|c|}
\hline & Speaker & Loop & Message \\
\hline 1 & $\mathrm{OC}$ & $\mathrm{OC}$ & EMCS OC my loop \\
\hline 2 & EMCS & OC & Go ahead \\
\hline 3 & $\mathrm{OC}$ & $\mathrm{OC}$ & $\begin{array}{l}\text { Yeah we were wondering about the EMCS activity this afternoon, } \\
\text { if you guys decided uh if you want the crew to do anything about } \\
\text { the water cable? }\end{array}$ \\
\hline 4 & EMCS & OC & $\begin{array}{l}\text { There is actually nothing the crew can do at this moment } \\
\text { or between the runs now because it is so difficult to uh get } \\
\text { inside the EMCS if you are not opening the main doors so } \\
\text { we cannot do anything at this point unfortunately }\end{array}$ \\
\hline 5 & $\mathrm{OC}$ & $\mathrm{OC}$ & $\begin{array}{l}\text { There's no way that they can come in uh and take any photo of } \\
\text { the cable that's hanging down between the two rotors? }\end{array}$ \\
\hline 6 & EMCS & In room & Yes or no? (turns to team leader and the engineers) \\
\hline 7 & Operator 2 & In room & The images we saw were fine \\
\hline 8 & EMCS & OC & $\begin{array}{l}\text { Actually we have some nice photos of this issue so I am not } \\
\text { sure that will help anymore }\end{array}$ \\
\hline 9 & $\mathrm{OC}$ & $\mathrm{OC}$ & $\begin{array}{l}\text { Ok, and are you able to tell me from these photos if there is } \\
\text { anything to be done? }\end{array}$ \\
\hline 10 & EMCS & OC & $\begin{array}{l}\text { We are looking into it. We have video also of this issue so } \\
\text { we can go back and try to figure out what to do }\end{array}$ \\
\hline 11 & Operator 2 & In room & But for now there is no issue, right? That it's ok. \\
\hline 12 & EMCS & In room & No yes \\
\hline 13 & EMCS & OC & $\begin{array}{l}\text { For this- but- for the moment we cannot do anything. We } \\
\text { have to do the run } 2 \text { (inaudible) and we cannot do anything at } \\
\text { this- this particular moment }\end{array}$ \\
\hline 14 & EMCS & In room & I basically already said that (to Operator 2) \\
\hline 15 & Operator 2 & In room & Yeah but just that- it's safe \\
\hline 16 & $\mathrm{OC}$ & $\mathrm{OC}$ & $\begin{array}{l}\text { Ok = I copy that without the main door being open it is inaccessible } \\
\text { to do anything with the cable, I also copy that we are in the middle } \\
\text { of the Gravi } 2 \text { runs right now and uh you know uh we can't, we are } \\
\text { not able go in there and do anything. Uh are you able to tell from } \\
\text { your- from the pictures and video of any damages actually being } \\
\text { done to the cable? Have you been able to tell that yet? }\end{array}$ \\
\hline
\end{tabular}


(continued)

\begin{tabular}{|c|c|c|c|}
\hline & Speaker & Loop & Message \\
\hline 17 & EMCS & OC & $\begin{array}{l}\text { No. we have not seen any damages up to now but we need to } \\
\text { look in detail into the video and the pictures but uh for now } \\
\text { they don't look uh damaged. }\end{array}$ \\
\hline 18 & $\mathrm{OC}$ & $\mathrm{OC}$ & Ok copy that \\
\hline
\end{tabular}

\section{Excerpt 6: Loose water cable, continued}

For the second time now, the EMCS is being summoned to respond to inquiries about the loose cable (turn 3). The EMCS operator has not taken initiative to report on the voice loop since the last interaction, but the team has spent the time addressing the problem, studying video images and re-constructing the anomaly in an on-ground EMCS replica. In other words, the problem is being taken very seriously, but the operator has not reported this activity to the other positions in the network. The call from $\mathrm{OC}$ at this point indicates that the issue is still having the attention of the operating authorities in Huntsville, who are not reassured that it is being managed. The accounts given by the operator so far do not seem to be sufficient and therefore trigger follow-up questions and repeated rounds on the loop.

Again, the EMCS operator responds with a definite answer to the inquiry with a statement that excludes any practical solution to the problem, emphasizing that there is nothing the crew (the astronauts) can do ("at this moment or between the runs"). This time, however, he also provides an explanation for this ("so difficult to get inside it without opening main doors"), as opening the doors would interrupt the experiment and ruin the scientific data. As a consequence, ("so"), the operator again concludes that there is nothing that can be done.

OC, however, is not entirely content with this explanation and continues with a problem-solving approach, this time suggesting that there might be a way to get photos of the cable (turn 5). After a brief consultation with the rest of the EMCS team, the operator responds that there is no need for more photos (turn 8). However, his response is hedged, reflecting epistemic uncertainty ("I am not sure this will help anymore"), which gives the account a sense of uncertainty. The operator still gives no indication of the problem solving that is taking place in the control room based on the images, and he does not provide any additional information or reassurance that the measures taken are adequate and sufficient. The account's failure to reassure is reflected in yet another question from OC, who probes further into the status and usefulness of the photos that are currently available (turn 9). At this point, the operator in fact signals that they are working on solving the issue (turn 10 "we are looking into it") and adds the information that there is video that might be of use. However, the descriptions are still highly mitigated ("try to figure out") and does not reflect the focus and attention this issue is given in the backstage control room.

At this point, the video recording shows that the other EMCS operator (Operator2) is visibly uneasy, shifting in his chair and whispering in the background as Operator 1 
speaks on the loop (turn 11). He hints to his colleague that he should provide an assessment of risk and proposes the phrase "but for now it is not an issue". This is not picked up by Operator 1 and does not affect his next speaking turn on the loop. He repeats what he has stated before, in the same conclusive manner, that nothing can be done about the situation (turn 13). However, he whispers back to his colleague, off the loop, that he has already addressed the issue (turn 14), but Operator 2 specifies his meaning, that they should report that the situation is safe (turn 15). Once it was established that this was not a power cable, the main concern with this anomaly was the threat that the cable could get hooked to the fixed internal structure of the EMCS, potentially causing harm to the equipment and ruin the experiment.

This assessment turns out to be relevant, as OC in his next speaking turn addresses precisely the level of damage from the loose cable (turn 16). Operator 1 responds to this concern with an assessment (turn 17) that both states that there are no visible damages, but that also highlights the uncertainties still present and the need for further inquiry from the EMCS team. OC accepts this account and closes the conversation.

This episode illustrates the challenges that the operator faces when unexpected and unknown events occur. There are several participants in the network of control rooms that will be involved and concerned should there be a problem that might affect the overall operation of the ISS. The operator at the local site needs to be able to account for the situation and describe both the problem and the efforts being made to solve them. In this case, it took several rounds of question-answer sequences in order to for the operator to provide enough information for the OC to be reassured. The team did a series of analysis and troubleshooting activities backstage, but the accounts provided on the voice loop included neither this comprehensive work nor the team's tentative conclusion that there was little risk of causing damages. In this way, the accounts failed to address the uncertainties that had been created among the other positions.

\subsubsection{Failure to reassure the network hierarchy}

Examples 3 and 4 illustrate another aspect of the connection between accountability on the fly and the objective of guarding the experiment trajectory and real-time flow. Here, the accounts provided on the loop fail to reassure the other positions that the EMCS operators are doing the expected anticipatory work. The operator in example 3 (corrupted images) had not listened to the relevant loop and consequently missed the opportunity to be ahead of trouble. Once the situation was brought to the operator's attention, the account provided failed to address the uncertainty among others in the network regarding the image transmission. This leads to repeated questions and requests for confirmation, signaling uncertainty, not only in terms of the technical problem, but also in terms of the control room's ability to manage the situation. Had the operator picked up on the discussion mentioning the EMCS, the issue could have been managed and contained quickly with a short response.

Example 4 (loose water cable) shows a similar situation in which the operator is made aware of a technical problem, and then provides an account that does not 
sufficiently communicate the problem-solving actions that are in fact being taken in the control room. Another important implication of this is that it demonstrates how the surrounding organization seeks to mitigate this uncertainty through repeated scrutiny from the higher positions in the network. The second operator advising the active operator to say, "it is safe" and "for now it is not an issue", understands the need for reassurance and urges his colleague to downgrade the risk. In contrast to the first two examples, the objective of the operator is not to seek authority to mitigate action but to avoid escalation of problem perception among their partners. Their failure to do so, not only harms their accountability as competent members with control over their system, but also risks initiatives being taken that can disrupt their experiment and also draw resources from other activities.

\section{Discussion}

Voice loop communication plays an important role in the real-time articulation of activities on the ISS, supplementing real-time data feeds and asynchronous means of communications. As we have demonstrated, establishing accountability 'on the fly', through verbal means on the loop, is necessary for achieving the main concern of the operators; to keep the experiment trajectory running without interruption. The design of convincing and reassuring accounts on the voice loop system is important in situations of troubleshooting, and the operators' successes or failures to this end affect not only operations in the local control room, but potentially across the network of control rooms.

We have studied the interactional details of accounting for trouble on the voice loop, situated within the specific set of contextual traits that surround the ground control room. These include a highly conservative and risk averse organization focused on formal systems of accountability, the urgency and time constraints of trouble shooting in real time operations, and the position of the EMCS operators low in the hierarchy of the ESA and NASA organizations. All of these shape the operational leverage of the operators. The voice loop, a main coordinating technology in the real time phase, is a highly regulated communication channel allowing for only condensed, convention-bound to-the-point messages. The strategic shaping of these verbal accounts serves an important role in establishing and upholding the legitimacy of the operators and the control room at large in the interaction with other positions in the network.

The ability to construct institutionally workable accounts on the loop is crucial for being heard as competent and accountable members of the ground control network and for gaining gain permission and access to resources to conduct troubleshooting operations. The way the operators communicate on the loop is, for others, indicative of whether they are seen as able to play the role that is expected by their position.

The voice loop provides the operators and higher-level positions an opportunity to extract information and pick up relevant cues from a wide array of sources, in turn supporting coordination across levels and divisions. However, in contrast to other 
forms of mediated communication, for example video or telephone, the voice loop has significant constraints on the operators' opportunities for self-presentation. The one-at-a-time system does not give the speakers room for expanding their accounts as they are being produced. Repairs and hesitations need to be kept at a minimum in the interest of both time and attention of the receiving parties. Also the linguistic codes, in terms of standardized phrases and codes of politeness, must be expressed with a certain fluency in order to be heard as legitimate claims to competence. The examples we have shown in which the accounts prove to be inadequate, emphasize this point as the operators under pressure fail to attend to uncertainty that is experienced elsewhere in the network. This challenge might be amplified by the linguistic diversity that the distributed control rooms represent. The requirements of being "precise and concise" in a situation of problem-solving is challenging even for native speakers. In this context, the speaker needs to be able to produce a succinct and effective account with verbal means only, and as we have seen in the analysis, this account needs to respond to the concerns of other positions in the network. While accounting for known anomalies can be part of the training and preparation for experiment execution, accounting for unexpected events is an even greater challenge and might need to be approached in a different manner.

There is a strong emphasis in training and preparations on the semantics and the rules of the voice loop communication in the EMCS group. The group also reflects on interactional and relational dimensions of their communication on the loop, for example by discussing the possible effects of specific utterances. However, there is more to be achieved by emphasizing the interactional means for establishing accountability in training for operations, both for the EMCS operators and others. In example 4, Loose water cable, the uneasiness of Operator 2 indicates this interactional orientation to the effects of accounts being made (or not being made) on the loop. In contrast to Operator 1, he understands that the lack of a certain response will spread uncertainty among the other positions, so he whispers to him "Yeah but just that- it's safe". The downgrading of risk that is found in the accounts of known problems, such as unstable telemetry, also serve to shield the Flight Directors and other high-level positions from unnecessary rounds of clarifications and discussions.

This study complements previous studies of voice loop communication in space operations within CSCW and related fields by focusing on low-level positions in the network of ground control rooms. The Flight Directors studied by Patterson et al. $(1999)^{21}$ are at the top of the organizational hierarchy, they are recognized experts with a strong formal authority, and their interactions on the loop do not to the same degree need to establish their authority or legitimacy. The EMCS group, however, is at the fringes of the organization, at a low level of the hierarchy. They are experts on their own equipment, but they need to continuously reassure the organization that

\footnotetext{
${ }^{21}$ These studies are reported in several other publications with variations of the same group of researchers: Watts et al. (1996), Watts-Perotti and Woods (2007, 2009), Watts-Englert et al. (2018a, b); Patterson et al. (2008).
} 
they are in control of it and its implications for other systems. The operators are keenly focused on 'protecting the science' of their experiment and making sure that it gets the resources it needs and remains uninterrupted despite anomalies and unexpected events. When problems occur, they need both to return their system to a nominal state, but also their role and relations to the other operators. The operators at this level do, in other words, not only rely on the voice loop system for coordination, overhearing and information exchange. They also rely on successful verbal accounts for ensuring the necessary agency to intervene and solve problems as they occur and for avoiding unnecessary interventions to their system that might interfere with the experiment flow. While the technology is the same for all operators independent on formal position, the context of action is not. The technology is used in different ways, where we show how accounts from low-level operators solve distinct purposes to protect their system from "attention from above" or oppositely attract it. This expands on our previous understanding of voice loops as a technology for describing and coordinating problem solving. Where previous studies focus mainly on the nominal content and regulative rules of the voice loop communication, our study forefronts the interactional devices that low-level operators employ in order to display competence and ability to serve their function in the larger operation. This, in turn, awards them the necessary access and agency to solve problems.

The ISS organization is constantly concerned with risk, potential signals of upcoming problems or deviations, attempting to anticipate and stay ahead of possible problems. For the operators, demonstrating that they have control over the risks associated with their interventions and problem solving, is crucial to avoid unnecessary scrutiny and possibly delayed resolution to the problems. We have seen in the analysis how failure to appropriately design accounts and reassure the other positions can lead to increased scrutiny which again can potentially lead to escalation. ${ }^{22}$

In other organizations where identifiable people, not positions, interact, more stable forms of trust based on an individual's expertise or personal networks may serve similar functions as the swiftly established accountability we discuss here. In our case, however, the accountability of the position is established and continuously re-established in verbal exchanges on the voice loop. The network is too large and the personnel occupying the positions shift too frequently for personal relations to matter and persist. Thus, the leverage and action space for trouble shooting provided by higher positions in the operational hierarchy is not given to persons based on some general trust, but to positions based on defined responsibilities associated with their role and their continued ability to provide adequate accounts of their operational needs and their solutions.

\footnotetext{
${ }^{22}$ In contrast to our operators, the astronauts on the ISS have a recognized status and a visible identity, their faces visible on the live feeds and addressed by their first name. The communication on the loop between the astronauts and their designated contact control room position (PAYCOM) is informal, even sometimes playful, in tone.
} 
We have illustrated how two different approaches to accountability are needed for understanding the challenges of real time operations in this context. In the planning phases of experiments, procedures and systems for producing structural accountability are crucial (see also Johansen et al. 2016). However, within the temporal constraints of the real-time phase decisions must be made, and actions taken without the luxury of formal risk management. When trouble occurs in this phase, there is no time to do formal revisions of remediating actions, and risk must be managed in more dynamic and situationally contingent ways. ${ }^{23}$ Moreover, they are a group of positions communicating on the highly restricted medium of the voice loop. This means that verbal clues displaying competence, and ensuring other positions of control, is an essential way of keeping the real time coordination and trouble-shooting running smoothly, without having to go into more formalized ways of risk management, thus threatening the real time flow of the experiment.

Although the network of positions is strictly organized, the fleeting nature of accountability in real time operations has some parallels to "swift trust" in temporary groups (Meyerson et al. 1996; Curnin et al. 2015). This form of trust relies heavily on role clarity among the involved parties. Playing the Goffmanian role in a consistent manner, carefully managing the front stage appearance of control, is not a matter of hiding information or being untruthful, but about consciously designing accounts on the loop in a manner that fits the role and the expectations of the network. Accountability on the fly depends on the operator displaying, often through subtle cues, competence and control on behalf of his position. The impression he thus gives is, however, ephemeral and necessary to continuously re-establish and reaffirm in every exchange.

CSCW and related literatures have been instrumental in demonstrating how informal, situated and often improvised coordinative work is important for successful collaboration. But in organizations obsessed with control through formal systems (see Sgobba et al. 2018a, b and section 3 here), such practices represent a drift into terrains less charted by plans and systematic risk management. The improvisation and ad hoc coordination in the real time phase represent moments in which the structural modes of accountability fall short and must be supplemented by other means. As for the "swift trust" created in Meyerson et al.'s (1996) temporary organizations, we argue that role clarity, and the ability to play the role that the position requires is an essential element in this.

This interactionally achieved accountability does not replace structural forms. It is not a matter of either/or. In a discussion of two different modalities of articulation work, Schmidt and Simone (2000, p. 205) stress the interwoven nature of the two forms: "ad hoc alignment and improvisation on the basis of mutual awareness versus coordination in terms of a predefined flow of work". These two modalities of

\footnotetext{
${ }^{23}$ This is a prominent topic in the previously discussed HRO literature, and more recent theory on safety and reliability such as the Resilience Engineering strand (Hollnagel et el. 2006). See for example Roe and Schulman (2008) for a discussion of control room operators managing a power grid "operating on the edge".
} 
articulation work are according to them seamlessly meshed and blended in real life cooperative activities. Although the real time phase is clearly characterized by the former kind of articulation work, and the accompanying ways of ensuring accountability and control of risk are as we have shown largely interactional, this is inextricably entwined with the formal processes of accountability. This entwinement is best illustrated by the reference given to a PAR number in the first two accounts. The accounts are not only well-formulated, they also convincingly establish a sense of control by the reference to formally validated solutions.

Structured voice loop communication in the forms we have discussed here are found only in highly specialized settings. Consequently, one could expect that implications for our study outside such contexts would be few. However, as suggested by Aoki's (2007) discussions of Watts et al.'s (1996) study there might be implications to be drawn from such extreme cases to other settings, such as using overhearing to improve coordination in health services (Patterson et al. 2008). Moreover, the concept of 'accountability on the fly' contributes to discussions of how formalized bureaucratic control in time critical settings can be supplemented with ways of achieving and displaying accountability through interactional means. For the group we have studied, our project has led to an intensification of the reflection and training on these issues, not only focusing on rules and conventions of voice loop communication but increasingly on the strategic design of accounts in light the role of the EMCS in the network. Our study has implications besides space operations in this respect. For example for emergency responders' radio communication, which would clearly benefit from such reflection and training.

\section{Conclusion}

Troubleshooting during space research operations requires an amount of situationally contingent improvisation and coordination, pressed by temporal constraints. In an organization geared towards control of risk through formal means of accountability and prospectively seeking to anticipate "what can possibly go wrong?" (Johansen et al. 2016), these situations represent a challenge. Their temporal constraints and situational specifics mean that they cannot be fully validated and controlled by formal methods in advance. Inspired by the way the term accountability is discussed in ethnomethodology, and the micro-analysis of accounts in Conversation Analysis, we have shown how an interactional approach to accountability serves as a supplement to formal means in real time operations.

In the context of space operations, coordination in troubleshooting situations is heavily dependent on a very narrow and highly regulated communication channel, namely the voice loop technology. This system is designed for real-time exchange of short, concise voice messages between the participants in the distributed network of operators on the ground and the astronauts in space. Within these constraints, we have shown show how the group of operators in the EMCS control room, a group positioned low in the hierarchy of formal authority, design their accounts on the voice 
loop, and how such accounts not only convey specific and targeted information, but also serve a role in the establishment of accountability in the network.

The accountability that is displayed in the voice loop interactions provides the operators with the necessary leverage to conduct their work, to get permission to do interventions on their system and to access to necessary resources, thus enabling them to keep the trajectory of their biological experiment on track. Unsuccessful accounts, which threaten their position and legitimacy in the network, immediately draws attention from higher level positions and leads to extended rounds of questions concerning risk and potentially delay or interruption of the experiment flow. The paper provides insight into the interactional and relational aspects of communication in contexts in which lower level positions need to design their verbal accounts strategically to seek or avoid attention in hierarchical, risk-averse organizations. The fact that the real-time trouble shooting in operations is conducted by a set of positions manned by rotating personnel, rather than identified professionals or experts, give the verbal accounts additional weight in terms of establishing and reestablishing accountability.

Despite the highly specific context, ground control of biological experiments on the international space station, this paper highlights an issue with broader significance for risk averse organizations: the manner in which accountability is established in time critical situations of troubleshooting and improvisation, in situations where formal systems of control are insufficient. The interactional production and negotiations of accountability is highly relevant for understanding the complex ways in which problems are solved and decisions made in complex, high-risk organizational environments.

Space research is a costly activity, meticulously planned to reduce the risk to a minimum. In the real time phases, when experiments are conducted, the temporal flow of the experiment necessitates modes of control that allow for timely interventions to expected and unexpected issues. These are precarious situations for the organization, as it needs to balance the control of risk with the flexibility to act swiftly on unexpected issues without disrupting the experiment trajectory. We have shown how verbal interactions on the voice loop, between low-level operators and the hierarchy of positions in the ground control network, are a part of this balancing act. An effective operator does not only need the technical competence required of the system, but also needs to be able to communicate strategically in ways that ensure other positions in the network of his competence, and that his system is under control. In this phase, smooth operations and effective trouble shooting depends on 'accountability on the fly' produced and reproduced in verbal interactions in the voice loop.

Open Access This article is licensed under a Creative Commons Attribution 4.0 International License, which permits use, sharing, adaptation, distribution and reproduction in any medium or format, as long as you give appropriate credit to the original author(s) and the source, provide a link to the Creative Commons licence, 
and indicate if changes were made. The images or other third party material in this article are included in the article's Creative Commons licence, unless indicated otherwise in a credit line to the material. If material is not included in the article's Creative Commons licence and your intended use is not permitted by statutory regulation or exceeds the permitted use, you will need to obtain permission directly from the copyright holder. To view a copy of this licence, visit http:// creativecommons.org/licenses/by/4.0/.

\section{References}

Agre, Philip E. (1994). Accountability and Discipline: A Comment on Suchman and Winograd. Computer Supported Cooperative Work (CSCW), vol. 3, no. 1, pp. 31-35.

Almklov, Petter G. (2018). Situated Practice and Safety as Objects of Management. In C. Bieder; C. Gilbert; B. Journé; and H. Laroche (eds): Beyond Safety Training. Paris: Springer, pp. 59-72.

Almklov, Petter G.; and Stian Antonsen (2014). Making Work Invisible: New Public Management and Operational Work in Critical Infrastructure Sectors. Public Administration, vol. 92, no. 2, pp. 477-492.

Antaki, Charles (1994). Explaining and Arguing: The Social Organization of Accounts. London: SAGE.

Aoki, Paul. M. (2007). Does Voice Coordination Have to be 'Rocket Science'? In Erickson and McDonald (eds): HCI Remixed: Reflections on Works that have Influenced the HCI Community. Cambridge, Massachusetts: The MIT Press, pp.179-184.

Barley, Steven. R. (1996). Technicians in the Workplace: Ethnographic Evidence for Bringing Work into Organizational Studies. Administrative Science Quarterly, vol. 41, no. 3, pp. 404-441.

Bossen, Claus (2011). Accounting and Co-Constructing: The Development of a Standard for Electronic Health Records. Computer Supported Cooperative Work (CSCW), vol. 20, no. 6, pp. 473-495.

Buttny, Richard (1993). Social Accountability in Communication. London: SAGE.

Button, Graham (ed). (1993). Technology in Working Order: Studies of Work, Interaction, and Technology. New York: Routledge.

Caldwell, Barret S. (2005) Analysis and Modeling of Information Flow and Distributed Expertise in Space-Related Operations. Acta Astronautica, vol. 56, pp. 996-1004.

Casler, James G. (2014). Revisiting NASA as a High Reliability Organization. Public Organization Review, vol. 14, no. 2, pp. 229-244.

Clarke, Adele. E. (2015). Anticipation Work: Abduction, Simplification, Hope. In G. C. Bowker; S. Timmermans; A. E. Clarke; and E. Balka (eds): Boundary objects and beyond: Working with Leigh Star. Cambridge, Massachusetts: The MIT Press, pp. 85-120.

Curnin, Steven; Owen, Christine; Paton, Douglas; Trist, Cain; and David Parsons (2015). Role Clarity, Swift Trust and Multi-Agency Coordination. Journal of Contingencies and Crisis Management, vol. 23, no. 1, pp. 29-35.

Dekker, Sidney (2014). The Bureaucratization of Safety. Safety Science, vol. 70, pp. 348-357.

Dekker, Sidney (2017). The Safety Anarchist: Relying on Human Expertise and Innovation, Reducing Bureaucracy and Compliance. London: Routledge.

Garfinkel, Harold (1967). Studies in Ethnomethodology. Englewood Cliffs, NJ: Prentice-Hall.

Goffman, Erving (1959). The Presentation of Self in Everyday Life. New York: Doubleday.

Goffman, Erving (1981). Forms of Talk. Philadelphia: University of Pennsylvania Press. 
Goodwin, Charles; and Marjorie Goodwin (1996), Seeing as Situated Activity: Formulating Planes. In Y. Engeström; and D. Middleton (eds): Cognition and Communication at Work. New York: Cambridge University Press, pp. 61-95.

Heath, Christian; and Paul Luff (1992). Collaboration and Control. Crisis Management and Multimedia Technology in London Underground Line Control Rooms. Computer Supported Cooperative Work (CSCW), vol. 1, nos. 1-2, pp. 69-94.

Heath, Christian; and Paul Luff (2000). Technology in Action. Cambridge: Cambridge University Press.

Heritage, John (1988). Explanations as Accounts: A Conversation Analytic Perspective. In C. Antaki (ed): Analyzing Lay Explanation: A Casebook of Methods. London: SAGE, pp. 127-144.

Hoeppe, Götz (2019). Mediating Environments and Objects as Knowledge Infrastructure. Computer Supported Cooperative Work (CSCW), vol. 28, nos. 1-2, pp. 25-59.

Hollnagel, Erik; Woods, David. D.; and Nancy Leveson (eds). (2006). Resilience Engineering: Concepts and Precepts. Aldershot, UK: Ashgate.

Hutchins, Edwin; and Tove Klausen (1996). Distributed Cognition in an Airline Cockpit. In Y. Engström; and D. Middleton (eds): Cognition and Communication at Work. New York: Cambridge University Press, pp. 15-34.

Jefferson, Gail; Drew, Paul; Heritage, John; Lerner, Gene; and Anita Pomerantz (eds). (2015). Talking About Troubles in Conversation. Oxford: Oxford University Press.

Johansen, Jens P.; Almklov, Petter G.; and Abdul Basit Mohammad (2016). What Can Possibly Go Wrong? Anticipatory Work in Space Operations. Cognition, Technology \& Work, vol. 18, no. 2, pp. 333-350.

LaPorte, Todd. R.; and Paula. M. Consolini (1991). Working in Practice but not in Theory: Theoretical Challenges of "High-Reliability Organizations". Journal of Public Administration Research and Theory: J-PART, vol. 1, no. 1, pp. 19-48.

Malakis, Stathis; Kontogiannis, Tom; and Barry Kirwan (2010). Managing Emergencies and Abnormal Situations in Air Traffic Control (Part II): Teamwork Strategies. Applied Ergonomics, vol. 41 , no. 4 , pp. 628-635.

Meyerson, Debra; Weick, Karl E.; and Roderick M. Kramer (1996). Swift Trust and Temporary Groups. In R. M. Kramer; and T. Tyler (eds): Trust in Organizations: Frontiers of Theory and Research. Thousand Oaks, CA: SAGE, pp. 166-195.

Mohammad, Abdul Basit; Johansen Jens P.; and Petter G. Almklov (2014). Reliable Operations in Control Centers, an Empirical Study. In R.D.J.M. Steenbergen; P.H.A.J.M. van Gelder; S. Miraglia; and A.C.W.M. Vrouwenvelder (eds): Safety, Reliability and Risk Analysis: Beyond the Horizon: Proceedings of the European Safety and Reliability Conference. London: CRC Press, pp.

Moore, Robert. J.; Ducheneaut, Nicholas; and Eric Nickell (2007). Doing Virtually Nothing: Awareness and Accountability in Massively Multiplayer Online Worlds. Computer Supported Cooperative Work (CSCW), vol. 16, no. 3, pp. 265-305.

Mulgan, Richard (2000). 'Accountability': An Ever-Expanding Concept? Public Administration, vol. 78 , no. 3 , pp. $555-573$.

Nevile, Maurice (2004). Beyond the Black Box: Talk-in-Interaction in the Airline Cockpit. Aldershot, UK: Ashgate.

Orbuch, Terri L. (1997). People's Accounts Count: The Sociology of Accounts. Annual Review of Sociology, vol. 23, no. 1, pp. 455-478.

Patterson, Emily. S.; Watts-Perotti, Jennifer; and David D. Woods (1999). Voice Loops as Coordination Aids in Space Shuttle Mission Control. Computer Supported Cooperative Work (CSCW), vol. 8, no. 4, pp. 353-371.

Patterson, Emily. S.; Watts-Perotti, Jennifer; and David D. Woods (2008). Voice Loops: Engineering Overhearing. In C. P. Nemeth (ed): Improving Healthcare Team Communication: Building on Lessons from Aviation and Aerospace. Aldershot, UK: Ashgate, pp. 79-96. 
Perrow, Charles. (1984) Normal Accidents. Living with High Risk Technologies. New York: Basic Books.

Pollock, Neil, and Williams, Robin. (2010). E-Infrastructures: How Do We Know and Understand Them? Strategic Ethnography and the Biography of Artefacts. Computer Supported Cooperative Work (CSCW), vol. 19, no. 6, pp. 521-556.

Pomerantz, Anita (1986). Extreme Case Formulations: A Way of Legitimizing Claims. Human Studies, vol. 9, nos. 2-3, pp. 219-229.

Power, Michael (1994). The Audit Explosion. London: Demos.

Power, Michael (2007). Organized Uncertainty: Designing a World of Risk Management. Oxford: Oxford University Press.

Redaelli, Iilaria; and Anotella Carassa (2018). New Perspectives on Plans: Studying Planning as an Instance of Instructed Action. Computer Supported Cooperative Work (CSCW), vol. 27, no. 1, pp. 107-148.

Resnick, Lauren. B.; Säljö, Roger; Pontecorvo, Clotilde; and Barbara Burge (eds). (1997). Discourse, Tools, and Reasoning: Essays on Situated Cognition. Berlin: Springer-Verlag.

Robinson, Jefferey. D. (2016). Accountability in Social Interaction. Oxford: Oxford University Press.

Roe, Emery; and Paul R. Schulman (2008). High Reliability Management: Operating on the Edge. Stanford University Press.

Rosness, Ragnar; Evjemo, Tor. E.; Haavik, Torgeir; and Irene Wærø (2016). Prospective Sensemaking in the Operating Theatre. Cognition, Technology \& Work, vol. 18, no. 1, pp. 53-69.

Sacks, Harvey; Schegloff, Emanuel A.; and Gail Jefferson (1974). A Simplest Systematics of the Organization of Turn-Taking for Conversation. Language, vol. 50, pp. 696-735.

Schmidt, Kjeld; and Liam Bannon (1992). Taking CSCW Seriously. Computer Supported Cooperative Work (CSCW), vol. 1, nos. 1-2, pp. 7-40.

Schmidt, Kjeld; and Carla Simone (2000). Mind the Gap. Towards a unified view of CSCW. In COOP2000: The Fourth International Conference on the Design of Cooperative Systems, Sophia Antipolis, France, 23-26 May 2000. IOS Press, pp. 205-221.

Scott, Marvin. B.; and Stanford. M. Lyman (1968). Accounts. American Sociological Review, vol. 33, no. 1, pp. 46-62.

Sgobba, Tommasso; Kanki, Barbara G.; Jean-Francois Clervoy; and Gro M. Sandal (eds) (2018a). Space Safety and Human Performance. Butterworth-Heinemann.

Sgobba, Tommaso; Levenson, Nancy; Wilde, Paul; and Stephanie Barr (2018b) System Safety and Accident Prevention. In S. Sgobba; B. Kanki; J-F Clervoy; and G. M. Sandal (eds): Space Safety and Human Performance. Oxford, UK: Butterworth-Heineman, pp. 273-353.

Starbuck, William and Farjoun, Moshe (eds). (2005). Organization at the Limit: Lessons from the Columbia Disaster. Oxford, UK: Wiley-Blackwell.

Steinhardt, Stephanie B.; and Steven J. Jackson (2015). Anticipation Work: Cultivating Vision in Collective Practice. Proceedings of the 18th ACM Conference on Computer Supported Cooperative Work \& Social Computing, Vancouver, Canada, 14 - 18 March 2015. New York: ACM Press, pp. 443-453.

Strauss, Anselm (1985). Work and the Division of Labor. The Sociological Quarterly, vol. 26, no. 1, pp. 1-19.

Suchman, Lucy (1997). Centers of Coordination: A Case and some Themes. In L. B. Resnick; R. Säljö; C. Pontecorvo; and B. Burge (eds): Discourse, Tools, and Reasoning: Essays on Situated Cognition. Berlin: Springer-Verlag, pp. 41-62.

Suchman, Lucy A. (2007). Human-Machine Reconfigurations. Plans and Situated Actions (2nd edition). Cambridge: Cambridge University Press.

Vaughan, Diane (1996). The Challenger Launch Decision: Risky Technology, Culture, and Deviance at NASA. Chigago, Illinois: University of Chicago Press. 
Watts, Jennifer C.; Woods, David D.; Corban, James M.; Patterson, Emily S.; Kerr, Ronald L.; and LaDessa C. Hicks (1996). Voice Loops as Cooperative Aids in Space Shuttle Mission Control. CSCW '96. Proceedings of the ACM conference on Computer supported cooperative work, 1996. New York: AMC Press, pp. 48-56

Watts-Englert, Jennifer; Woods David, D.; and Emily S. Patterson (2018a). Human spaceflight mission control centers. S. Sgobba; B. Kanki; J-F Clervoy; and G. M. Sandal (eds): Space Safety and Human Performance. Oxford, UK: Butterworth-Heineman, pp. 573-580.

Watts-Englert, Jennifer; Woods, David D.; and Emily S. Patterson (2018b). Resilient Anomaly Response in Mission Control Center. In S. Sgobba; B. Kanki; J-F Clervoy; and G. M. Sandal (eds): Space Safety and Human Performance. Oxford, UK: Butterworth-Heineman, pp. 581-591.

Watts-Perotti, Jennifer; and David D. Woods (2007). How anomaly response is distributed across functionality distinct teams in space Shuttle mission control. Journal of Cognitive Engineering and Decision Making, vol.1, no. 4, pp. 405-433

Watts-Perotti, Jennifer; and David D. Woods (2009). Cooperative Advocacy: An Approach for Integrating Diverse Perspectives in Anomaly Response. Computer Supported Cooperative Work (CSCW), vol. 18, nos. 2-3, pp. 175-198.

Weick, Karl E.; and Kathleen M. Sutcliffe (2007). Managing the Unexpected: Resilient Performance in an Age of Uncertainty. San Francisco, California: John Wiley \& Sons.

Whalen, Jack (1995). Expert Systems versus Systems for Experts: Computer-Aided Dispatch as a Support System in Real-World Environments. In P. J. Thomas (ed): The Social and Interactional Dimensions of Human Computer Interfaces. Cambridge: Cambridge University Press, pp. 161-183.

Zimmerman, Don. H. (1992). The Interactional Organization of Calls for Emergency Assistance. In P. Drew, and J. Heritage (eds): Talk at Work. Interaction in Institutional Settings. Cambridge: Cambridge University Press, pp. 418-469.

Publisher's Note Springer Nature remains neutral with regard to jurisdictional claims in published maps and institutional affiliations. 